\title{
$\mathrm{HDO}$ and $\mathrm{SO}_{2}$ thermal mapping on Venus
}

\section{The $\mathrm{SO}_{2}$ spatial distribution above and within the clouds}

\author{
T. Encrenaz ${ }^{1}$, T. K. Greathouse ${ }^{2}$, M. J. Richter ${ }^{3}$, J. Lacy ${ }^{4}$, T. Widemann ${ }^{1}$, B. Bézard ${ }^{1}$, T. Fouchet ${ }^{1}$, \\ C. deWitt $^{3}$, and S. K. Atreya ${ }^{5}$ \\ ${ }^{1}$ LESIA, Observatoire de Paris, CNRS, UPMC, Univ. Denis Diderot, 92195 Meudon, France \\ e-mail: therese.encrenaz@obspm.fr \\ 2 SWRI, Div. 15, San Antonio, TX 78228, USA \\ 3 Physics Department, University of California, Davis, CA 95616, USA \\ 4 Department of Astronomy, University of Texas at Austin, TX 78712-1083, USA \\ 5 Department of Atmospheric, Oceanic and Space Science, University of Michigan, Ann Arbor, MI 48109-2143, USA
}

Received 11 July 2013 / Accepted 23 September 2013

\section{ABSTRACT}

\begin{abstract}
Sulfur dioxide and water vapor, two key species of Venus photochemistry, are known to exhibit significant spatial and temporal variations above the cloud top. In particular, ground-based thermal imaging spectroscopy at high spectral resolution, achieved on Venus in January 2012, has shown evidence for strong $\mathrm{SO}_{2}$ variations on timescales shorter than a day. We have continued our observing campaign using the TEXES high-resolution imaging spectrometer at the NASA InfraRed Telescope Facility to map sulfur dioxide over the disk of Venus at two different wavelengths, $7 \mu \mathrm{m}$ (already used in the previous study) and $19 \mu \mathrm{m}$. The $7 \mu \mathrm{m}$ radiation probes the top of the $\mathrm{H}_{2} \mathrm{SO}_{4}$ cloud, while the $19 \mu \mathrm{m}$ radiation probes a few kilometers below within the cloud. Observations took place on October 4 and 5, 2012. Both $\mathrm{HDO}$ and $\mathrm{SO}_{2}$ lines are identified in our 7- $\mu \mathrm{m}$ spectra and $\mathrm{SO}_{2}$ is also easily identified at $19 \mu \mathrm{m}$. The $\mathrm{CO}_{2}$ lines at 7 and $19 \mu \mathrm{m}$ are used to infer the thermal structure. An isothermal/inversion layer is present at high latitudes (above $60 \mathrm{~N}$ and S) in the polar collars, which was not detected in October 2012. The enhancement of the polar collar in October 2012 is probably due to the fact that the morning terminator is observed, while the January data probed the evening terminator. As observed in our previous run, the HDO map is relatively uniform over the disk of Venus, with a mean mixing ratio of about 1 ppm. In contrast, the $\mathrm{SO}_{2}$ maps at $19 \mu \mathrm{m}$ show intensity variations by a factor of about 2 over the disk within the cloud, less patchy than observed at the cloud top at $7 \mu \mathrm{m}$. In addition, the $\mathrm{SO}_{2}$ maps seem to indicate significant temporal changes within an hour. There is evidence for a cutoff in the $\mathrm{SO}_{2}$ vertical distribution above the cloud top, also previously observed by SPICAV/SOIR aboard Venus Express and predicted by photochemical models.
\end{abstract}

Key words. planets and satellites: atmospheres - infrared: planetary systems - planets and satellites: general

\section{Introduction}

The sulfur and water chemical cycles are known to play a key role in the atmospheric chemistry of Venus (Mills et al. 2007; Krasnopolsky 2007; Zhang et al. 2012). Below the clouds, $\mathrm{H}_{2} \mathrm{O}$ and $\mathrm{SO}_{2}$ are both present with mixing ratios of about 30 ppm and 100-150 ppm, respectively (see Bézard \& de Bergh 2007, for a review). Both species are transported from the deep troposphere above the main cloud deck by Hadley convection (Prinn \& Fegley 1987) and are deeply depleted above the $\mathrm{H}_{2} \mathrm{SO}_{4}$ cloud by photodissociation and condensation processes. The mixing ratio of $\mathrm{H}_{2} \mathrm{O}$ above the clouds is in the range of 1-2 ppm (Fedorova et al. 2008), i.e. 15-30 times less than below the clouds. The $\mathrm{SO}_{2}$ mixing ratio above the clouds has been found to be $10-100 \mathrm{ppb}$ from Venera 15 and Pioneer Venus measurements (Zasova et al. 1993) and more recently in the 10-1000 ppb range by SPICAV aboard Venus Express (Marcq et al. 2011), i.e. hundreds to a thousand times less than below the clouds.

Over the past six years, the photochemistry and dynamics of the Venus mesosphere have been extensively monitored by the Venus Express mission, supported by ground-based campaigns. In particular, large latitudinal and temporal variations of the $\mathrm{SO}_{2}$ abundance have been reported from the data recorded by
SPICAV-UV, SPICAV/SOIR and VIRTIS aboard Venus Express (Marcq et al. 2011; Belyaev et al. 2012). In order to bring complementary informations about the spatial and temporal evolution of minor species on Venus, we have started an observing campaign using the high-resolution imaging spectrometer TEXES in the thermal infrared range. Indeed, while space orbiter observations usually cover a small part of the planet with high spatial resolution at a given local hour, ground-based imaging spectroscopy allows the simultaneous mapping of the Venus disk. The first campaign took place on January 10-12, 2012 at the InfraRed Telescope Facility (IRTF). Maps of HDO and $\mathrm{SO}_{2}$ were simulatenously recorded at $7.35 \mu \mathrm{m}$ with a spatial resolution of 1.5 arcsec and a spectral resolving power of about 80000 . Assuming a $\mathrm{D} / \mathrm{H}$ ratio of 200 times the terrestrial value (Fedorova et al. 2008), we derived a $\mathrm{H}_{2} \mathrm{O}$ mixing ratio of $1.5+/-0.75 \mathrm{ppm}$, with no significant variations over the disk nor over a timescale of two days. In contrast, the $\mathrm{SO}_{2}$ maps showed strong variations over the Venus disk, by a factor as high as 5 , and also strong variations over a timescale of a day. The maximum local abundance of $\mathrm{SO}_{2}$ ranged between 50 and $175 \mathrm{ppb}$ over the three days.

In this paper, we report the results of a new campaign with the same instrument, which took place on October 4-5, 2012 
at IRTF. We had a double objective: first, investigate if $\mathrm{SO}_{2}$ variations could be found over a timescale shorter than a day, and second, search for $\mathrm{SO}_{2}$ at two different wavelengths, probing different altitude levels in the Venus atmosphere. In addition to the $7-\mu \mathrm{m}$ range previously observed in January 2012, we also selected a spectral interval at $19 \mu \mathrm{m}$, where the radiation probes a few kilometers below, within the $\mathrm{H}_{2} \mathrm{SO}_{4}$ cloud. $\mathrm{SO}_{2}$ was easily detected and mapped in the two spectral ranges and HDO was again mapped at $7 \mu \mathrm{m}$. Three main conclusions can be derived from this study: (1) the thermal structure shows evidence for a clear isothermal/inversion region above the cloudtop at high latitudes, which was not seen in January 2012; (2) there is evidence for a strong depletion of the $\mathrm{SO}_{2}$ mixing ratio as a function of altitude above the clouds; (3) the $\mathrm{SO}_{2}$ maps show a noticeable variation over a timescale in the order of an hour. Observations and modelling are described in Sect. 2. Results are presented in Sect. 3 and discussed in Sect. 4.

\section{Observations and modelling}

TEXES is an infrared imaging spectrometer operating between 5 and $25 \mu \mathrm{m}$ which combines high spatial (about 1.5 to 2 arcsec) and spectral $(R=80000)$ resolution (Lacy et al. 2002). In January 2012, we mapped the disk of Venus with the TEXES instrument at IRTF, with the prime objective of detecting and mapping sulfur dioxide and water vapor (through its tracer HDO), and monitoring the temporal variations of these two species (Encrenaz et al. 2012a, hereafter referred as E12). Our method consists of ratioing the line depths of the weak minor species with weak neighboring transitions of $\mathrm{CO}_{2}$. It allows us to cancel, to first order, the effects associated with the calibration, the geometry, and the atmospheric parameters (Encrenaz et al. 2008). This method was first successfully used on Mars to monitor hydrogen peroxide and water vapor (Encrenaz et al. 2012b) and to infer an upper limit of $\mathrm{SO}_{2}$ (Encrenaz et al. 2011).

\subsection{Observations}

On October 4 and 5, 2012, we observed Venus in two spectral ranges, at $1343-1353 \mathrm{~cm}^{-1}(7.4 \mu \mathrm{m})$ and at $529-531 \mathrm{~cm}^{-1}$ $(19 \mu \mathrm{m})$, which correspond to the $v_{3}$ and $v_{2}$ bands of $\mathrm{SO}_{2}$ respectively. The continuum at these two wavelengths is constrained by the extinction cross section of the $\mathrm{H}_{2} \mathrm{SO}_{4}$ particles of the cloud. As shown by Zasova et al. (1993), this coefficient is about 2.5 times stronger at $7 \mu \mathrm{m}$ than at $19 \mu \mathrm{m}$; the $19-\mu \mathrm{m}$ radiation thus probes a few kilometers deeper than the $7-\mu \mathrm{m}$ radiation. A third band, $v_{1}$ at $1150 \mathrm{~cm}^{-1}(8.7 \mu \mathrm{m})$, probes higher levels as the extinction coefficient is three times stronger than at $7 \mu \mathrm{m}$; unfortunately the band is weak and the depletion of $\mathrm{SO}_{2}$ above the cloud would make the detection of the $\mathrm{SO}_{2}$ lines very difficult at this wavelength. Venus was observed over two nights (October 4 and 5,2012). The diameter of Venus was 15.3 arcsec and its illumination factor was $72.5 \%$. Its Doppler velocity was $+12 \mathrm{~km} \mathrm{~s}^{-1}$, corresponding to a Doppler shift of $-0.054 \mathrm{~cm}^{-1}$ at $1350 \mathrm{~cm}^{-1}$ and $-0.021 \mathrm{~cm}^{-1}$ at $530 \mathrm{~cm}^{-1}$. The spectral resolving power was about 84000 at $1350 \mathrm{~cm}^{-1}$ and 53000 at $530 \mathrm{~cm}^{-1}$, corresponding to spectral resolutions of $0.016 \mathrm{~cm}^{-1}$ and $0.010 \mathrm{~cm}^{-1}$, respectively. The width slit of the instrument ( $1 \operatorname{arcsec}$ at $7 \mu \mathrm{m}$ and $2 \operatorname{arcsec}$ at $19 \mu \mathrm{m}$ ) was aligned along the north-south celestial axis and moved from west to east by 0.5 -arcsec steps in order to map the planetary disk. At $7 \mu \mathrm{m}$, the slit length was 5 arcsec and the scans were repeated three times, from north to south, in order to map the whole planet. Each scan was recorded in about $15 \mathrm{~min}$ so that, including overheads, a full map was obtained in about 50

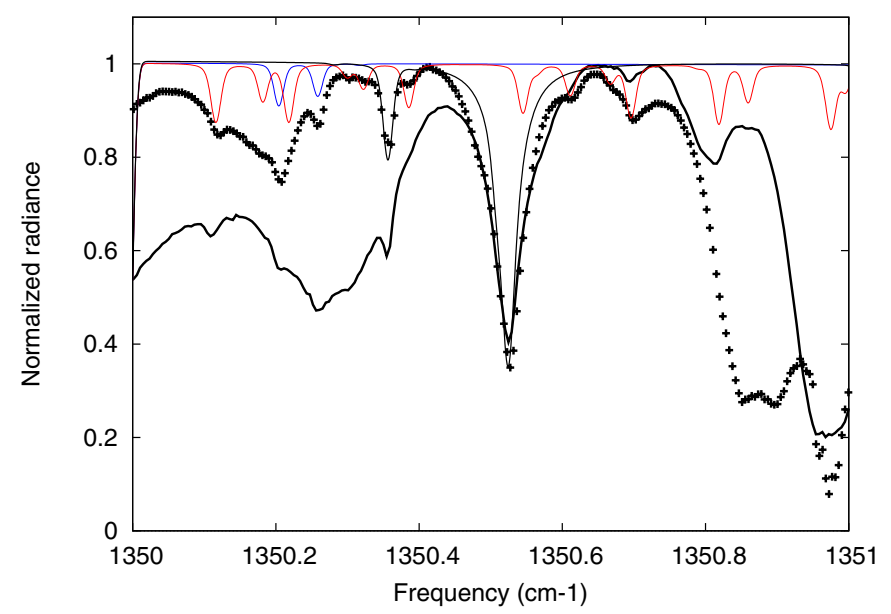

Fig. 1. Spectrum of Venus recorded by TEXES, integrated over the whole disk, covering the $1350-1351 \mathrm{~cm}^{-1}$ range. TEXES Data: January data (black crosses), October data (thick black line). The spectral resolution is $0.016 \mathrm{~cm}^{-1}$. Models: $\mathrm{CO}_{2}$ (thin black line), $\mathrm{HDO}$ (3 ppm, thin blue line), $\mathrm{SO}_{2}$ (thin red line, $100 \mathrm{ppb}$ ). Both TEXES spectra are Doppler shifted and the abcissa axis is rest frequencies. The difference between the Doppler shifts is about $0.1 \mathrm{~cm}^{-1}$. The broad absorption features are due to terrestrial contamination. It can be seen that this contamination is much stronger in October than in January, so that the two HDO lines detected in January at 1350.20 and $1350.26 \mathrm{~cm}^{-1}$ are not detected in October. Two $\mathrm{SO}_{2}$ lines remain detected around $1350.12 \mathrm{~cm}^{-1}$ and $1350.69 \mathrm{~cm}^{-1}$.

$\min$. At $19 \mu \mathrm{m}$, the slit length was about 12 arcsec and a single scan was taken in $15 \mathrm{~min}$, centered on the equator. The 7- $\mu \mathrm{m}$ observations were taken between 17:00 and 19:00 UT, and the 19- $\mu \mathrm{m}$ observations were taken between 19:00 and 21:00 UT. The data were processed following the procedure used for the Mars observations (Encrenaz et al. 2004). Weather conditions were poor, with some temporary cloud coverage and a high water content, sometimes as high as $8 \mathrm{pr}-\mathrm{mm}$, and significantly limited the quality of the $7-\mu \mathrm{m}$ data. In contrast, the $19-\mu \mathrm{m}$ range, which shows no terrestrial contamination, was much less affected by the poor weather conditions.

In the $1343-1353 \mathrm{~cm}^{-1}$ spectral range, the spectrum of Venus is dominated by a $\mathrm{CO}_{2}$ isotopic band that probes the lower mesosphere above the cloudtop, typically at altitudes of $60-80 \mathrm{~km}$. All other strong absorption features present in the TEXES spectrum are due to telluric absorption (mostly $\mathrm{H}_{2} \mathrm{O}$ and $\mathrm{CH}_{4}$ in the Earth's atmosphere). In this spectral range, we concentrate on spectral intervals outside these strong telluric absorptions to study $\mathrm{HDO}$ and $\mathrm{SO}_{2}$ in the Venus mesosphere. In the $529-531 \mathrm{~cm}^{-1}$ spectral range, free of telluric absorption, the Venus spectrum shows strong and weak transitions of $\mathrm{CO}_{2}$, and a few transitions of $\mathrm{SO}_{2}$, but no $\mathrm{HDO}$ transition.

Figure 1 shows the spectrum of Venus integrated over the whole disk on October 5, 2012 between 1350.0 and $1351.0 \mathrm{~cm}^{-1}$, compared with the same spectrum recorded on January 11, 2012. Both spectra have been Doppler-shifted to show rest frequencies. Synthetic spectra of Venus, including contributions from $\mathrm{CO}_{2}, \mathrm{HDO}$ and $\mathrm{SO}_{2}$, are shown for comparison. There are two main differences between the two observed spectra: (1) The Doppler shifts were in opposite directions, so that the terrestrial absorption features are shifted by about $0.1 \mathrm{~cm}^{-1}$ between the two spectra; (2) the telluric absorption is much stronger in October 2012. The two effects prevent the detection of the two HDO lines which were used in January 2012. For the present study, as described below, we have used the 
T. Encrenaz et al.: $\mathrm{HDO}$ and $\mathrm{SO}_{2}$ mapping on Venus

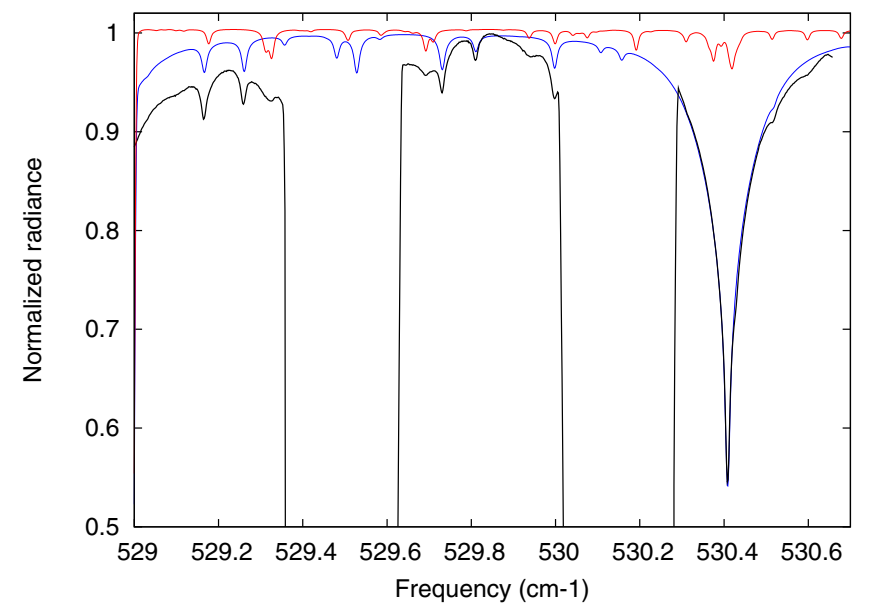

Fig. 2. Spectrum of Venus recorded by TEXES on October 5, 2012 (20:10 UT), integrated over the whole disk, between 529.1 and $530.6 \mathrm{~cm}^{-1}$ range (black line). The spectral resolution is $0.010 \mathrm{~cm}^{-1}$. Models: $\mathrm{CO}_{2}$ (blue), $\mathrm{SO}_{2}(100 \mathrm{ppb}$, red). Three weak $\mathrm{SO}_{2}$ lines are detected around $529.32,529.7$ and $529.95 \mathrm{~cm}^{-1}$. It can be seen that the observed lines are broader than the modelled ones, while the weak $\mathrm{CO}_{2}$ lines are well fitted by the model. This suggests that the $\mathrm{SO}_{2}$ mixing ratio decreases as the altitude increases (see text).

only available line of $\mathrm{HDO}$, at $1344.9 \mathrm{~cm}^{-1}$. In the case of $\mathrm{SO}_{2}$, we have used also more favorable signatures, the $\mathrm{SO}_{2}$ doublet at $1345.10-1345.13 \mathrm{~cm}^{-1}$, and a neighboring transition at $1345.28 \mathrm{~cm}^{-1}$ (see below, Sect. 4.3).

Figure 2 shows the spectrum of Venus on October 5, integrated over the whole disk, beetwen 529.1 and $530.6 \mathrm{~cm}^{-1}$. Due to the optical configuration of the instrument, the spectral range covered at $19 \mu \mathrm{m}$ is much smaller than at $7 \mu \mathrm{m}$ and the different Fabry-Perot orders do not overlap. Synthetic models of Venus including $\mathrm{CO}_{2}$ and $\mathrm{SO}_{2}$ are shown for comparison. A strong line and four weak lines of $\mathrm{CO}_{2}$ are easily detected as well as two blends of $\mathrm{SO}_{2}$ transitions, at 529.32 and $529.70 \mathrm{~cm}^{-1} . \mathrm{SO}_{2}$ is also detected at $529.95 \mathrm{~cm}^{-1}$ and in the wing of the strong $\mathrm{CO}_{2}$ line, at 530.46 and $530.60 \mathrm{~cm}^{-1}$. It can be seen immediately that the $\mathrm{SO}_{2}$ observed transitions are broader than the model, which assumes a constant mixing ratio of $\mathrm{SO}_{2}$ over altitude. This effect is discussed in more detail below.

\subsection{Modelling}

The synthetic spectra of Venus were calculated using a radiative transfer line-by-line code without scattering, also used in our first analysis (E12). The effect of scattering is expected to be negligible in the radiative transfer because, at mid infrared wavelengths, the single scattering albedo in the upper cloud is expected to be very low. Indeed, using the cloud model of Crisp (1986) with mode 1 and 2 spherical particles of $\mathrm{H}_{2} \mathrm{SO}_{4}$ at 75 percent concentration, we calculate a mean single scattering albedo of 0.074 at both 7.4 and $19 \mu \mathrm{m}$.

Spectroscopic data were taken from the GEISA data bank (Jacquinet-Husson et al. 2009) for the line intensities of the $7-\mu \mathrm{m}$ band. For the intensities of the $\mathrm{SO}_{2}$ and $\mathrm{CO}_{2}$ lines at $19 \mu \mathrm{m}$, we used the HITRAN database (Rothman et al. 2005). Indeed, we noticed some discrepancies between the intensities of the weak $\mathrm{CO}_{2}$ lines at $929-931 \mathrm{~cm}^{-1}$ reported by the two data bases (by as much as 50 percent in the case of the $\mathrm{CO}_{2}$ transition at $529.81 \mathrm{~cm}^{-1}$ ), and a better fit of the relative intensities with the TEXES data was obtained in the case of the HITRAN

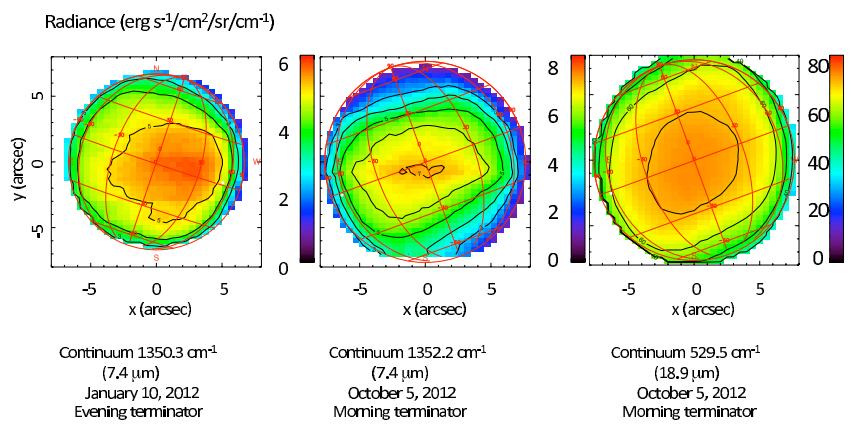

Fig. 3. Maps of the continuum in January and October 2012. Left: continuum at $1350.3 \mathrm{~cm}^{-1}$, January 10,2012 . In this figure, already shown in E12, the north-south axis has been corrected. Middle: continum at $1352.2 \mathrm{~cm}^{-1}$, October 5, 2012. Right: continuum at $529.5 \mathrm{~cm}^{-1}$, October 5, 2012.

data. The self-broadening coefficients of $\mathrm{CO}_{2}$ were taken from the GEISA database. In the case of $\mathrm{HDO}$ and $\mathrm{SO}_{2}$, for which the broadening coefficients by $\mathrm{CO}_{2}$ are not given in the data bases, we multiplied the GEISA broadening coefficients by $\mathrm{N}_{2}$ by a factor 1.4 (Nakazawa \& Tanaka 1982). For the temperature dependence of the broadening coefficients, we used $n=-0.75$ for $\mathrm{CO}_{2}$ and $\mathrm{SO}_{2}$ (Bézard et al. 1990), and -0.35 for HDO (Varanasi 1971). The thermal profile was retrieved from the simultaneous fitting of the $\mathrm{CO}_{2}$ strong and weak lines.As a starting point, we used a thermal profile derived from our analysis of the VIRTIS$\mathrm{H}$ data in the $\mathrm{CO}(1-0)$ band at $4.7 \mu \mathrm{m}$, which also probes the atmosphere at the cloudtop (Encrenaz et al. 2011). As expected, this first guess profile is very close to the profile retrieved by Irwin et al. (2008) at the equator, using VIRTIS-M data. The derived atmospheric model assumes a cloud top of infinite opacity at $57 \mathrm{~km}$, with a cloud top temperature of $241 \mathrm{~K}$ and a pressure of $250 \mathrm{mbar}$ at this level.The temperature of the cloudtop is chosen to fit the maximum absolute value of the continuum at $19 \mu \mathrm{m}\left(70 \mathrm{erg} / \mathrm{s} / \mathrm{cm}^{2} / \mathrm{sr} / \mathrm{cm}^{-1}\right)$. In our thermal model, the temperatures are $215 \mathrm{~K}$ and $192 \mathrm{~K}$ at altitudes of $70 \mathrm{~km}$ and $80 \mathrm{~km}$, respectively. In order to fit the $1350 \mathrm{~cm}^{-1}$ spectral range, the same thermal profile is used with a cloud top at $62 \mathrm{~km}$, i.e. $5 \mathrm{~km}$ higher. At this level, the temperature is $231 \mathrm{~K}$ and the pressure is $100 \mathrm{mbar}$; this altitude is chosen so that the temperature fits the maximum $7-\mu \mathrm{m}$ continuum $\left(7 \mathrm{erg} / \mathrm{s} / \mathrm{cm}^{2} / \mathrm{sr} / \mathrm{cm}^{-1}\right)$. The pressure scale is constrained by the shape and depth of the strong and weak $\mathrm{CO}_{2}$ lines.

\section{Data analysis and results}

\subsection{Thermal structure}

Information about the thermal structure can be retrieved from the continuum maps and from the maps of the $\mathrm{CO}_{2}$ line depths. The weak $\mathrm{CO}_{2}$ lines probes the atmospheric region just above the cloud top. Thus, the 7- $\mu \mathrm{m} \mathrm{CO}_{2}$ map probe the $60-80 \mathrm{~km}$ region (see E12, Fig. 2), while the 19- $\mu$ m map probes a few kilometers below. Figure 3 shows the continuum maps recorded in January 2012 at $7 \mu \mathrm{m}$, in October 2012 at $7 \mu \mathrm{m}$ and in October 2012 at $19 \mu \mathrm{m}$. Figure 4 shows maps of a weak $\mathrm{CO}_{2}$ line depth for the same 3 data sets. The $\mathrm{CO}_{2}$ lines used for these maps are at $529.73 \mathrm{~cm}^{-1}$ and $1345.22 \mathrm{~cm}^{-1}$ for the October maps, and $1350.4 \mathrm{~cm}^{-1}$ for the January map. It can be seen that both October maps show that the $\mathrm{CO}_{2}$ line depth is close to zero at latitudes higher than 60 degrees, both north and south. In contrast, the January $7-\mu \mathrm{m}$ map does not show this effect, or just a hint of it. The same trend is shown for the continuum maps 


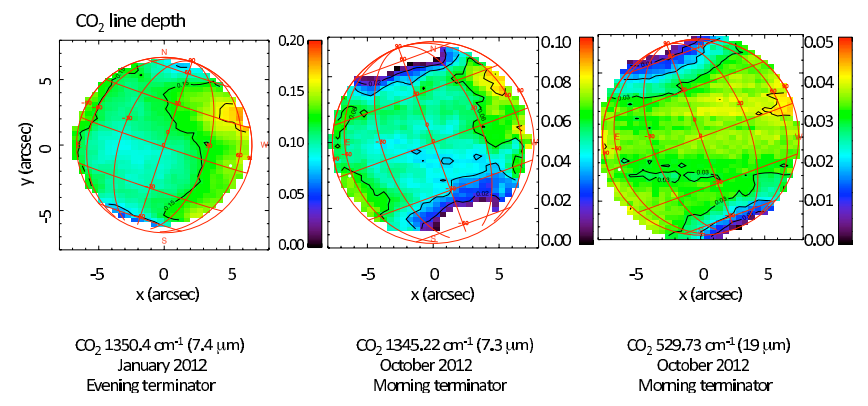

Fig. 4. Maps of the $\mathrm{CO}_{2}$ line depth in January and October 2012. Left: $\mathrm{CO}_{2}$ transition at $1350.4 \mathrm{~cm}^{-1}$, January 2012. In this figure, already shown in Encrenaz et al. (2012a), the north-south axis has been corrected. Middle: $\mathrm{CO}_{2}$ transition at $1345.22 \mathrm{~cm}^{-1}$, October 2012. Right: $\mathrm{CO}_{2}$ transition at $529.73 \mathrm{~cm}^{-1}$, October 2012 .

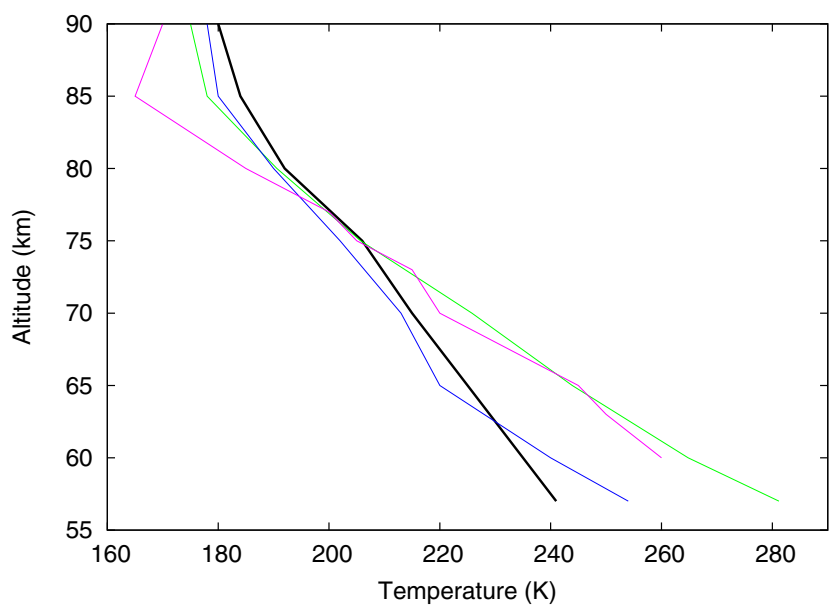

Fig. 5. Thermal profile of Venus at low latitude used in the calculations. Thick black line: Nominal profile, which provides the best fit for the integrated spectrum shown in Fig. 2. With a cloud level at $62 \mathrm{~km}(T=$ $231 \mathrm{~K}$ ), it also fits the 7- $\mu \mathrm{m}$ data of October 2012. Blue: thermal profile retrieved at the equator from the VIRTIS-M CO data at $4.7 \mu \mathrm{m}$ (Irwin et al. 2008). Magenta: VIRA thermal profile at the equator (Seiff et al. 2005). Green: VeRa profile obtained near the equator (Lee et al. 2012; Piccialli et al. 2012).

(Fig. 3) where the continuum decrease at high latitude is more pronounced in October than in January 2012; on the October data, it is also more clearly visible at $7 \mu \mathrm{m}$ (i.e. at the cloud top) than at $19 \mu \mathrm{m}$ (a few kilometers below, within the cloud). We have to mention that a sign error along the north-south axis was discovered in the January maps published in E12. The January maps are plotted again in the present paper with the proper axis orientation.

The absence of weak $\mathrm{CO}_{2}$ lines at high latitudes in the October data implies that the atmospheric thermal profile above $60 \mathrm{~km}$ has to be isothermal or may possibly exhibit an inversion. Figure 5 shows the nominal thermal profile used to fit the averaged 19- $\mu$ m spectrum (Fig. 2), which also fits well the $\mathrm{CO}_{2}$ lines near the equator. Figure 6 shows two thermal profiles used to fit the high latitude TEXES data. The first one shows an isothermal region at $T=220 \mathrm{~K}$ between $57 \mathrm{~km}$ and $72 \mathrm{~km}$, and the second one shows an inversion, with a temperature of $220 \mathrm{~K}$ at $57 \mathrm{~km}$ and $225 \mathrm{~K}$ at $65 \mathrm{~km}$. Figures 7 and 8 show the corresponding fits, for the strong $\mathrm{CO}_{2}$ line at $530.4 \mathrm{~cm}^{-1}$ (Fig. 7) and the two weak $\mathrm{CO}_{2}$ lines at 529.73 and $529.81 \mathrm{~cm}^{-1}$ (Fig. 8) respectively. Three TEXES spectra have been selected at latitudes $0,70 \mathrm{~N}$ and $70 \mathrm{~S}$. We show here the $70 \mathrm{~S}$ data, which are similar to the $70 \mathrm{~N}$ ones.

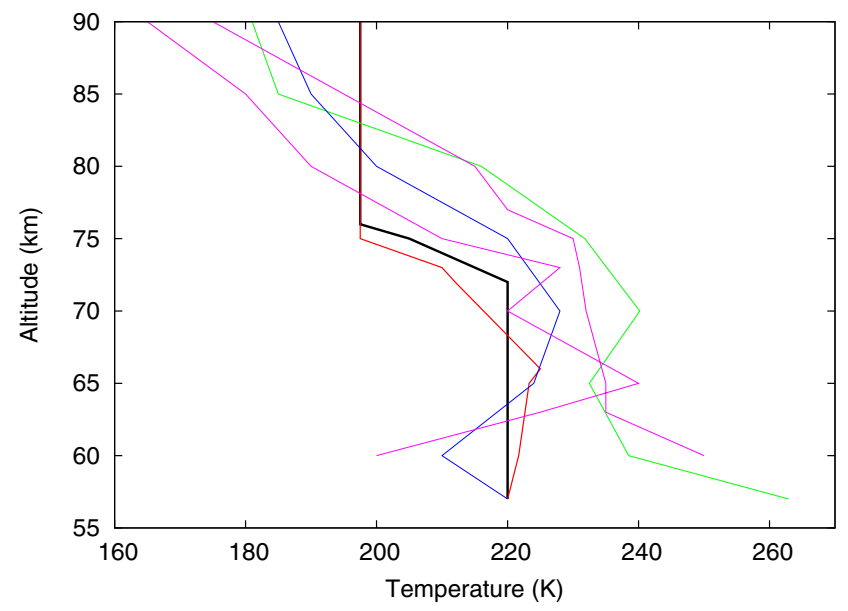

Fig. 6. Thermal profiles of Venus at high latitude ( $70 \mathrm{~N}$ and $\mathrm{S})$ used in the calculations. Thick black line: nominal thermal profile, characterized by a constant temperature of $220 \mathrm{~K}$ below $72 \mathrm{~km}$ and $198 \mathrm{~K}$ above $75 \mathrm{~km}$. This profile gives the best fit of the $19-\mu \mathrm{m} \mathrm{CO}_{2}$ lines at $70 \mathrm{~N}$ and $70 \mathrm{~S}$ latitudes. Red: inversion profile, with $T=220 \mathrm{~K}$ at $57 \mathrm{~km}, T=225 \mathrm{~K}$ at $66 \mathrm{~km}$ and $T=198 \mathrm{~K}$ above $75 \mathrm{~km}$. Blue: inversion profile retrieved at $4.7 \mu \mathrm{m}$ by Irwin et al. (2008) at $70 \mathrm{~S}$. Green: VIRA profile retrieved at high latitude (65-75 deg., Seiff et al. 1985). Magenta (left curve): VeRa profile retrieved at $68 \mathrm{~S}$ by Piccialli et al. (2012; Fig. 1). Magenta (right curve): VeRa profile reported at $68 \mathrm{~S}$ by Lee et al. for a specific orbit (2012, Fig. 1). The difference between the two VeRa profiles illustrates the local and temporal variations of the temperature profile in the polar collar.

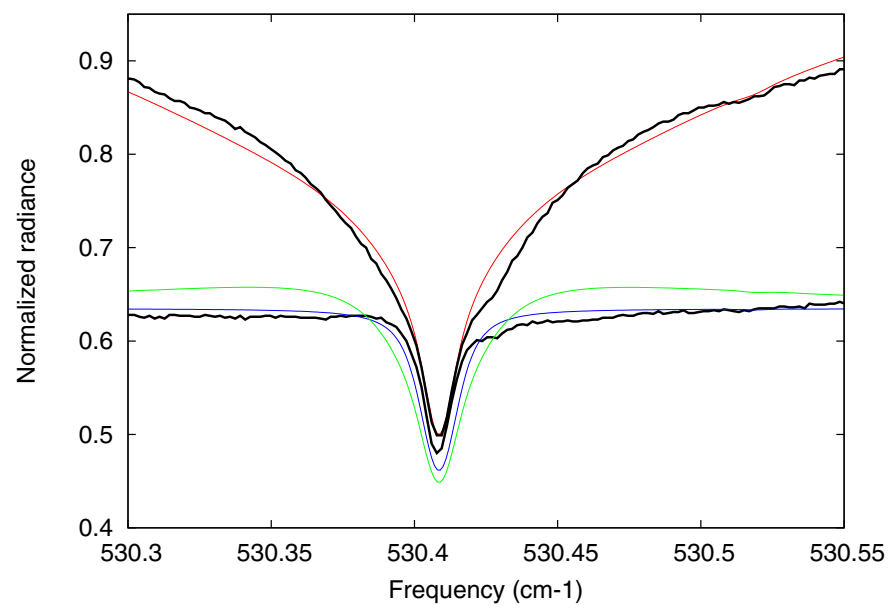

Fig. 7. Spectral fits of the strong $\mathrm{CO}_{2}$ line at $530.4 \mathrm{~cm}^{-1}$, at the equator and at high latitudes. Thick black lines: TEXES data. Models: nominal model (equator, red), isothermal model (high latitudes, best fit, blue), and inversion model (high latitudes, green).

The nominal thermal profile gives a good fit of the equatorial spectrum for both strong and weak lines. The isothermal profile fits very well the TEXES data at 70S, both for the continuum level and for the line depth. The fit provided by the inversion profile is not as good as the previous one, but in view of the uncertainty on the continuum definition at $19 \mu \mathrm{m}$ (see Fig. 2), we consider it as an upper limit of the possible inversion at high latitude. In conclusion, our data imply, for latitudes above 60 degrees, the presence of an isothermal/inversion layer above the cloud in the $60-75 \mathrm{~km}$ region, with a maximum inversion amplitude of $5 \mathrm{~K}$. The comparison with other thermal profiles retrieved by different means (Figs. 5 and 6) is discussed in Sect. 4. 
T. Encrenaz et al.: $\mathrm{HDO}$ and $\mathrm{SO}_{2}$ mapping on Venus

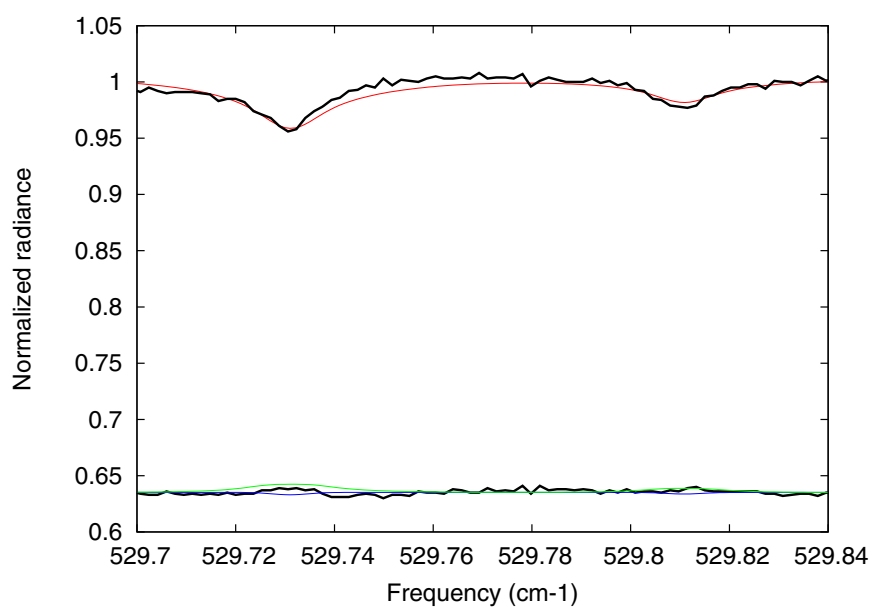

Fig. 8. Spectral fits of the two weak $\mathrm{CO}_{2}$ lines at 529.73 and $529.81 \mathrm{~cm}^{-1}$, at the equator and at high latitudes. Thick black lines: TEXES data. Models: nominal model (equator, red), isothermal model (high latitudes, best fit, blue), and inversion model (high latitudes, green).

$\mathrm{HDO} / \mathrm{CO}_{2}$ line depth ratio

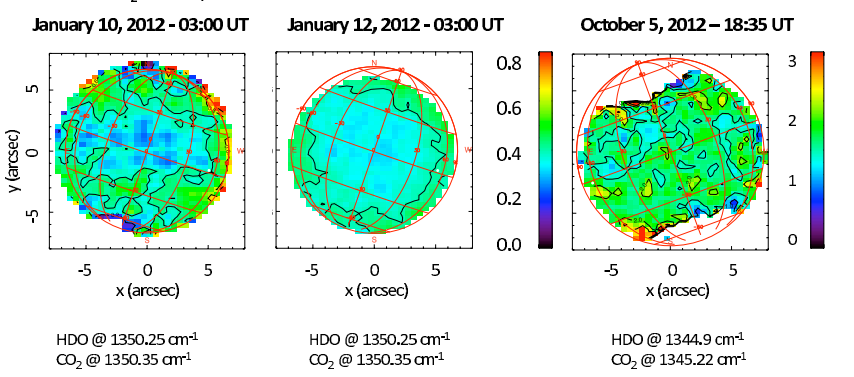

Fig. 9. Left and middle: $\mathrm{HDO} / \mathrm{CO}_{2}$ maps recorded on January 10 and 12, 2012, using the $\mathrm{HDO}$ transition at at $1350.25 \mathrm{~cm}^{-1}$ and the $\mathrm{CO}_{2}$ transition at $1350.35 \mathrm{~cm}^{-1}$. The orientation of the north-south axis has been corrected. Right: $\mathrm{HDO} / \mathrm{CO}_{2}$ map obtained on October 5, using the HDO line at $1344.90 \mathrm{~cm}^{-1}$ and the $\mathrm{CO}_{2}$ transition at $1345.22 \mathrm{~cm}^{-1}$. The three maps show a rather uniform spatial distribution, with variations less than about $+/-50 \%$.

\section{2. $H D O$}

The HDO maps obtained in January 10 and 12 (cf. E12) were built using the HDO transition at $1350.25 \mathrm{~cm}^{-1}$ and the $\mathrm{CO}_{2}$ transition at $1350.35 \mathrm{~cm}^{-1}$ (rest frequencies). We reproduce these maps in Fig. 9 (left and middle) with the north-south axis corrected. The HDO map obtained from the October data, using $\mathrm{HDO}$ at $1344.90 \mathrm{~cm}^{-1}$ and $\mathrm{CO}_{2}$ at $1345.22 \mathrm{~cm}^{-1}$, is also shown for comparison (Fig. 9, right). There is no evidence for temporal variation, neither on a short time scale (48 h) nor over a long time scale ( 9 months).

Figures 10 and 11 show the spectral fit of the HDO line at $1344.90 \mathrm{~cm}^{-1}$ for an averaged TEXES specctrum recorded on October 5. In Fig. 11, the continuum due to the wing of the telluric absorption line has been withdrawn. Our nominal profile (Fig. 5) is used in the calculation, with a layer of infinite opacity at $z=62 \mathrm{~km}(T=131 \mathrm{~K}, P=100 \mathrm{mbar})$. The best fit is obtained wih a constant $\mathrm{H}_{2} \mathrm{O}$ mixing ratio of $1 \mathrm{ppm}$, assuming that $\mathrm{D} / \mathrm{H}$ is 200 times the terrestrial value (Fedorova et al. 2008). Models corresponding to 1.25 and $0.75 \mathrm{ppm}$ are also shown for comparison (Fig. 11). We estimate the $\mathrm{H}_{2} \mathrm{O}$ mixing ratio as $1.0+/-0.25 \mathrm{ppm}$. This result is consistent with our result of the January 2012 run $\left(\mathrm{H}_{2} \mathrm{O}=1.5+/-0.75\right.$ ppm; cf. E12).

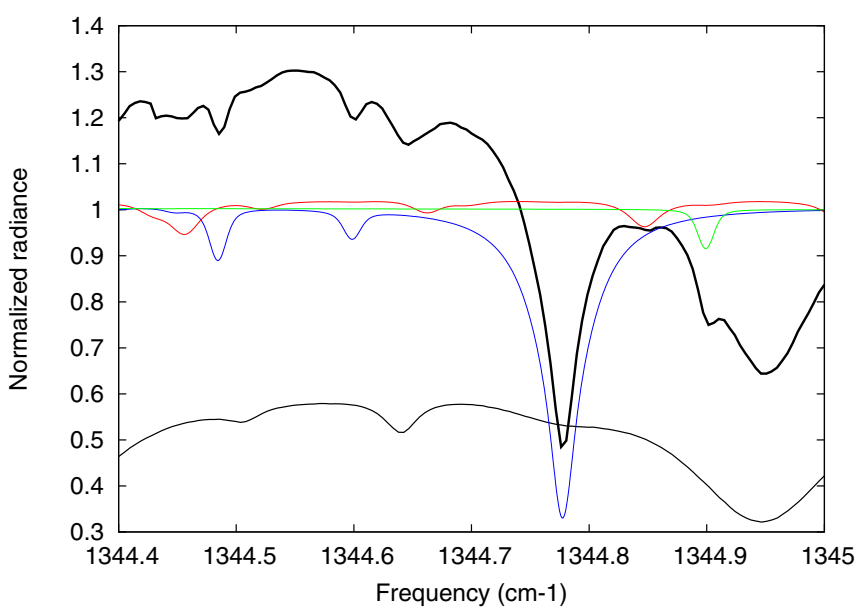

Fig. 10. TEXES disk-averaged spectrum taken on October 5, 18:35 UT, in the 1344.4-1345.0 $\mathrm{cm}^{-1}$ spectral range. Thick black line: TEXES data; thin black line: atmospheric telluric absorption. Models: Blue: Nominal model with $\mathrm{CO}_{2}$ contribution; red: $\mathrm{SO}_{2}$ contribution $(150 \mathrm{ppm}$ + cutoff at $67 \mathrm{~km}$, see text); green: $\mathrm{HDO}$ contribution $\left(\mathrm{H}_{2} \mathrm{O}=1 \mathrm{ppm}\right.$, $\mathrm{D} / \mathrm{H}=200 \mathrm{~T}$ ). The models are shown for the identification of the minor species.

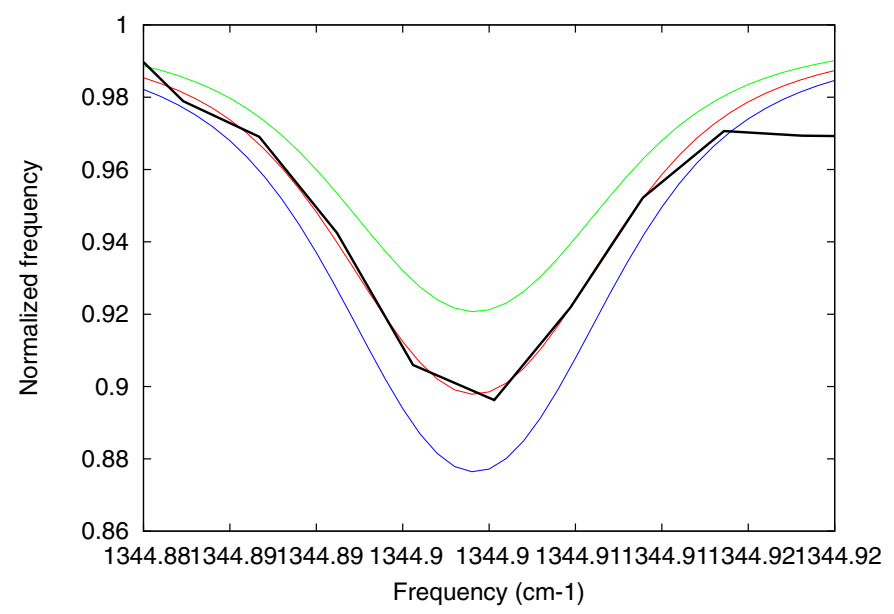

Fig. 11. HDO transition at $1344.90 \mathrm{~cm}^{-1}$ (rest frequency) after the removal of the continuum slope (black thick line) compared with three models: $\mathrm{HDO}=0.75 \mathrm{ppm}$ (green), $1 \mathrm{ppm}$ (red, best fit) and $1.25 \mathrm{ppm}$ (blue).

\section{3. $\mathrm{SO}_{2}$}

\subsection{1. $\mathrm{SO}_{2}$ spatial distribution}

At $7.4 \mu \mathrm{m}$, the $\mathrm{SO}_{2}$ maps were obtained using two $\mathrm{SO}_{2}$ absorption features, the doublet at $1345.12 \mathrm{~cm}^{-1}$ and the single line at $1345.28 \mathrm{~cm}^{-1}$, both associated with the $\mathrm{CO}_{2}$ line at $1345.22 \mathrm{~cm}^{-1}$. We have checked that using other $\mathrm{CO}_{2}$ transitions lead to consistent results. Figure 12 shows a set of three $\mathrm{SO}_{2}$ maps recorded in January 10-12, 2012 around $7.3 \mu \mathrm{m}$ and are separated by a timescale of 1 day; the maps, already shown in E12, are reproduced here with the north-south axis corrected. Figure 13 shows two maps recorded on October 5 at $7.4 \mu \mathrm{m}$, separated by a timescale of $100 \mathrm{~min}$. Each map is the average of two maps obtained with the two different $\mathrm{SO}_{2}$ transitions mentioned above, at $1345.12 \mathrm{~cm}^{-1}$ and $1345.28 \mathrm{~cm}^{-1}$, respectively. These two maps are also shown in Fig. 13 to illustrate the noise level of the data. It can be seen that there is a good agreement between the maps retrieved by each $\mathrm{SO}_{2}$ transition (the $1345.12 \mathrm{~cm}^{-1}$ 


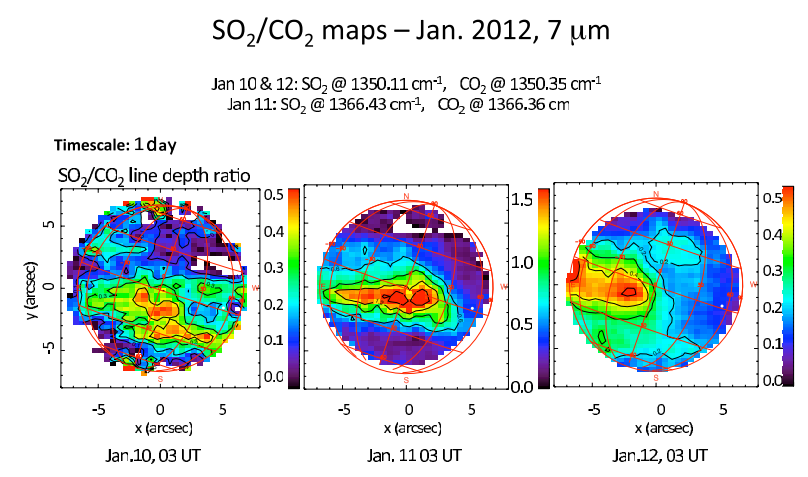

Fig. 12. From left to right, three $\mathrm{SO}_{2} / \mathrm{CO}_{2}$ maps recorded on January 10 , 11 and 12, 2012. We used for $\mathrm{SO}_{2}$ the $1350.16 \mathrm{~cm}^{-1}$ transition (Jan. 10 and 12) and the $1366.43 \mathrm{~cm}^{-1}$ transition (Jan. 11). For $\mathrm{CO}_{2}$, we used the $1350.4 \mathrm{~cm}^{-1}$ transition (Jan 10 and 12) and the $1366.36 \mathrm{~cm}^{-1}$ transition (Jan. 11). These maps, already published in E12, are shown here with the proper north-south axis orientation.

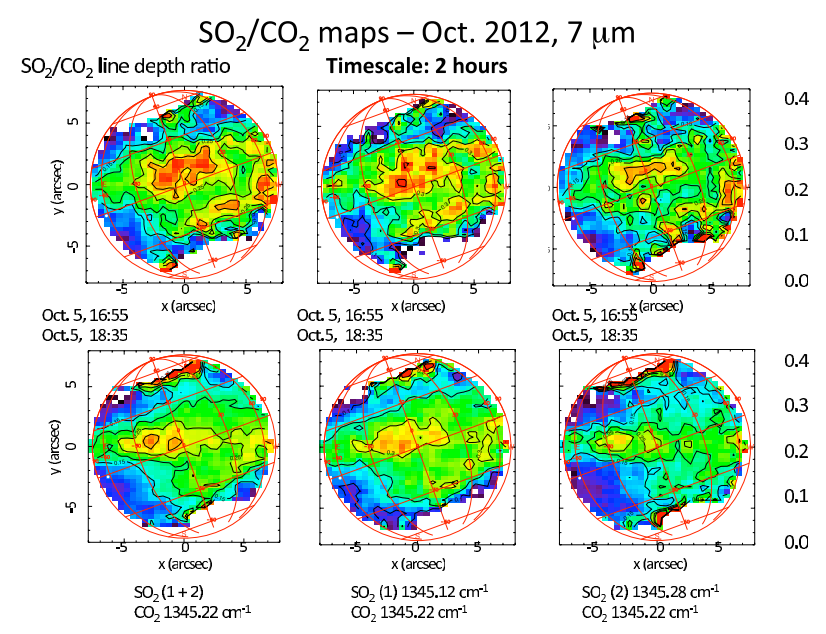

Fig. 13. $\mathrm{SO}_{2} / \mathrm{CO}_{2}$ maps recorded on October 5, 2012. Right: map obtained using the $\mathrm{SO}_{2}$ line at $1345.28 \mathrm{~cm}^{-1}$; middle: map obtained using the $\mathrm{SO}_{2}$ doublet at $1345.12 \mathrm{~cm}^{-1}$; in both cases, the $\mathrm{CO}_{2}$ line at $1345.22 \mathrm{~cm}^{-1}$ was used for comparison. Left: average of the two maps. Top: Oct.5, 16:55; bottom: Oct. 5, 18:35. In spite of the limited signalto-noise ratio, due to poor atmospheric conditions, there is evidence for actual temporal variations on timescales less than two hours.

transition being slightly stronger than the $1345.28 \mathrm{~cm}^{-1}$ one). In addition, both maps inferred from each transition indicate a decrease of the $\mathrm{SO}_{2}$ abundance within a timescale of 100 minutes.

As pointed out in $\mathrm{E} 12$, the $\mathrm{SO}_{2}$ maps show strong spatial variation in each map, with local variations by a factor as high as 5. The same behavior is observed on October 5, 2012. We already pointed out the temporal variations of the $\mathrm{SO}_{2}$ spatial distribution, which showed significant variations over a timescale of a day. The striking result of the present study is that these variations appear to occur on much shorter timescales, typically less than two hours.

A similar conclusion is reached from the analysis of the $19-\mu \mathrm{m} \mathrm{SO} \mathrm{S}_{2}$ maps. Figure 14 shows four maps recorded at $19 \mu \mathrm{m}$, two on Oct. 4 (19:40 UT and 20:10 UT), and two on October 5 (19:40 UT and 20:10 UT). The maps were built using the $\mathrm{SO}_{2}$ doublet at $529.70 \mathrm{~cm}^{-1}$ and the $\mathrm{CO}_{2}$ line at $529.73 \mathrm{~cm}^{-1}$. The two maps taken on October 5 are very similar. In contrast, the two earlier maps, taken on October 4, show significant differences over a large part of the disk. If confirmed, this result implies significant large-scale variations of $\mathrm{SO}_{2}$ over a timescale
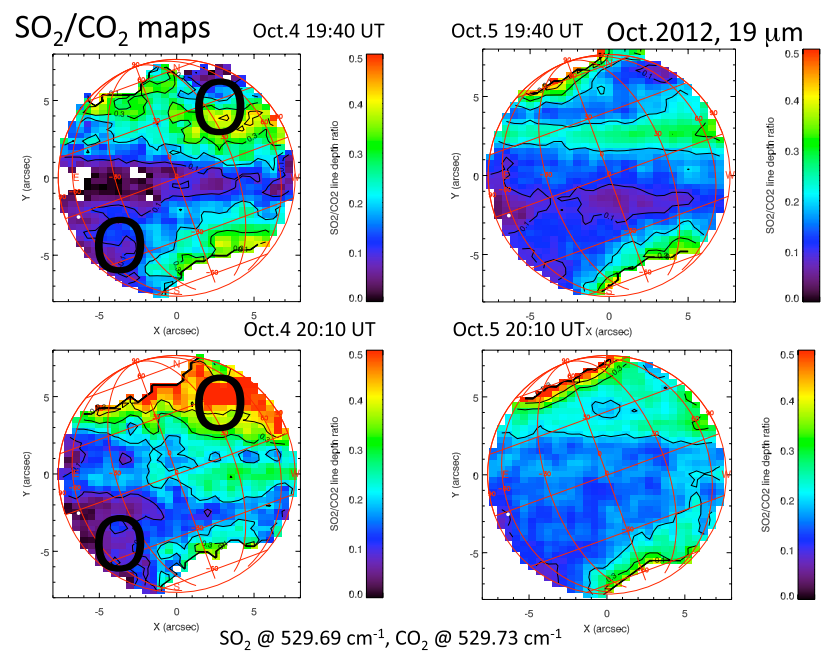

Fig. 14. Four $\mathrm{SO}_{2}$ maps recorded on October 4 and 5, 2012. Left: October 4; top: 19:40; bottom: 20:10. The black circles correspond to the locations of maximum and minimum $\mathrm{SO}_{2}$ abundances where the spectra shown in Fig. 18 have been analyzed. Right: October 5; top: 19:40; bottom: 20:10. We used for $\mathrm{SO}_{2}$ the $529.7 \mathrm{~cm}^{-1}$ doublet, and for $\mathrm{CO}_{2}$ the 529.73 transition (rest frequencies). In all cases, the $\mathrm{SO}_{2}$ spatial distribution appears less patchy than at $7 \mu \mathrm{m}$. The two maps of October 5 look very similar, but a strong increase in the $\mathrm{SO}_{2}$ abundance, spread over a large fraction of the disk, appears on the Oct.4, 20:10 UT map.

of only $30 \mathrm{~min}$. In all cases, the spatial variations of $\mathrm{SO}_{2}$ observed at $19 \mu \mathrm{m}$ (i.e. a few kilometers below the cloud-top level probed at $7 \mu \mathrm{m}$ ) appear to have less small-scale structures than observed at $7 \mu \mathrm{m}$, and the variations over the disk are within about a factor of 2 .

\subsection{2. $\mathrm{SO}_{2}$ abundance and vertical distribution}

Figure 15 shows a spectral fit of an averaged spectrum on October 5, $2012(18: 35 \mathrm{UT})$ in the $1345.2 \mathrm{~cm}^{-1}$ spectral region used for the $\mathrm{SO}_{2}$ study. As for HDO, we use our nominal thermal profile inferred from the $19-\mu \mathrm{m} \mathrm{CO}_{2}$ lines study (Fig. 5), with the introduction of a layer of infinite opacity at $z=62 \mathrm{~km}$. This thermal profile provides a good fit of the strong $\mathrm{CO}_{2}$ line at $1345.5 \mathrm{~cm}^{-1}$, as well as the weak $\mathrm{CO}_{2}$ lines at 1345.22 and $1345.34 \mathrm{~cm}^{-1}$. As already mentioned in the case of the $19-\mu \mathrm{m}$ data, the $\mathrm{SO}_{2}$ doublet around $1345.12 \mathrm{~cm}^{-1}$ appears broader than the model including a constant mixing ratio with altitude. As shown in Fig. 16, a better fit is obtained when a cutoff is introduced at an altitude of $67 \mathrm{~km}(T=220 \mathrm{~K})$.

The spectral fit of $\mathrm{SO}_{2}$ at $19 \mu \mathrm{m}$ leads to the same conclusions. For the two maps of October 4 , we have selected small areas of the Venus disk corresponding to regions where $\mathrm{SO}_{2}$ is maximum, and where $\mathrm{SO}_{2}$ is minimum. These areas are indicated on the 19- $\mu \mathrm{m} \mathrm{SO}_{2}$ maps (Fig. 14). Figure 17 shows a fit of the $\mathrm{SO}_{2}$ doublet at $529.7 \mathrm{~cm}^{-1}$ in the region of maximum $\mathrm{SO}_{2}$ for the map of Oct.4, 19:40 UT. Figure 17 shows that, in the region of maximum $\mathrm{SO}_{2}$ abundance, the best fit is obtained for a $\mathrm{SO}_{2}$ mixing ratio of $180 \mathrm{ppb}$, with a cutoff at $67 \mathrm{~km}$. It can be seen also that a $\mathrm{SO}_{2}$ vertical distribution using a constant mixing ratio leads to a poor fit of the spectrum. We thus conclude, from both the $7-\mu \mathrm{m}$ and the $19-\mu \mathrm{m}$ analyses, that the $\mathrm{SO}_{2}$ distribution is strongly depleted a few kilometers above the clouds. Models also show that the mixing ratio of $\mathrm{SO}_{2}$ above $67 \mathrm{~km}$ needs to be less than a few ppb in order to fit the data. 


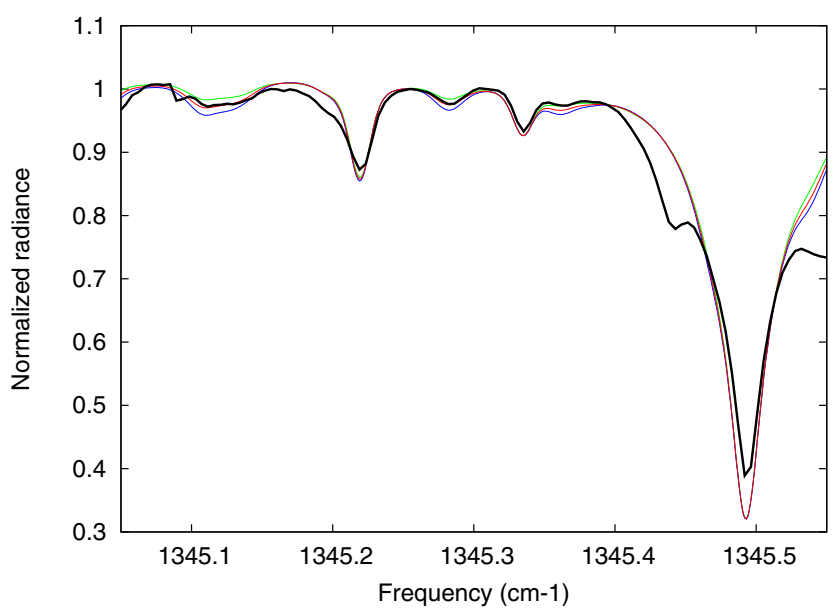

Fig. 15. TEXES disk-averaged spectrum taken on October 5, 18:35 UT, in the 1345.0-1345.6 $\mathrm{cm}^{-1}$ spectral range. Thick black line: TEXES data; thin lines: Models: Green: $\mathrm{SO}_{2}=100 \mathrm{ppb}+$ cutoff (see text below); red: $\mathrm{SO}_{2}=150 \mathrm{ppb}+$ cutoff; blue: $\mathrm{SO}_{2}=200 \mathrm{ppb}+$ cutoff.

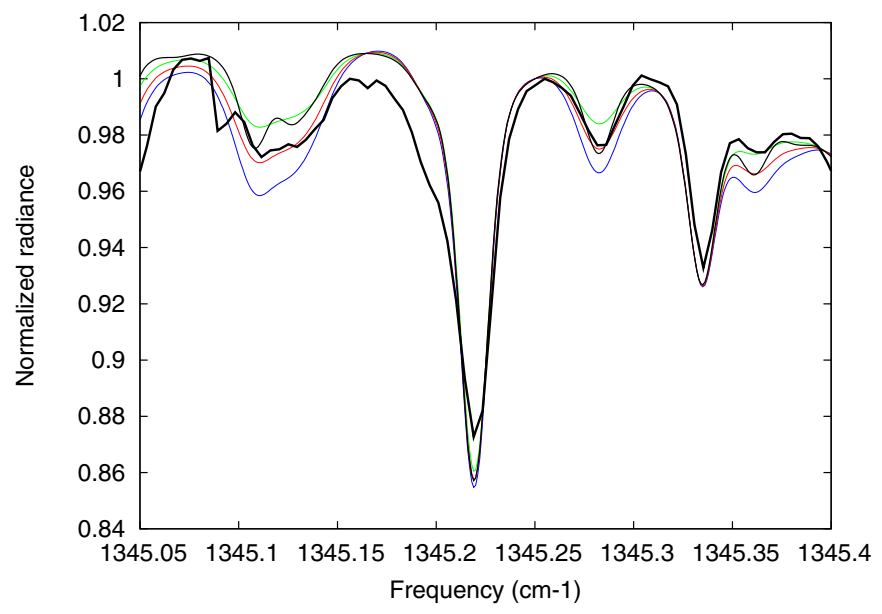

Fig. 16. $\mathrm{SO}_{2}$ transition at $1345.10 \mathrm{~cm}^{-1}$ (rest frequency, black thick line) compared with different models (thin lines): Green: $\mathrm{SO}_{2}=100 \mathrm{ppb}+$ cutoff (see text below); red: $\mathrm{SO}_{2}=150 \mathrm{ppb}+$ cutoff; blue: $\mathrm{SO}_{2}=$ $200 \mathrm{ppb}+$ cutoff. Black: constant $\mathrm{SO}_{2}$ mixing ratio, $\mathrm{SO}_{2}=50 \mathrm{ppb}$. The spike at $1345.09 \mathrm{~cm}^{-1}$ is an instrumental artefact ans was removed in the calculation of the line depth used to retrieve the $\mathrm{SO}_{2} / \mathrm{CO}_{2}$ map (Fig. 13, middle). It can be seen that the best fit is obtained when a cutoff is applied at $67 \mathrm{~km}$.

Figure 18 shows a comparison of three spectra taken on October 4: (1) maximum $\mathrm{SO}_{2}$ abundance, 19:40 UT; (2) maximum $\mathrm{SO}_{2}$ abundance, 20:10 UT; (3) minimum $\mathrm{SO}_{2}$ abundance, 20:10 UT. The locations of maximum and minimum $\mathrm{SO}_{2}$ abundances are indicated on the two maps (Fig. 14) and correspond to the same latitudes and longitudes for the two dates. The spectrum of minimum $\mathrm{SO}_{2}$ abundance at 19:40 UT (not shown in Fig. 18) is identical to the one of minimum $\mathrm{SO}_{2}$ abundance at 20:10 UT. Figure 18 shows that the two regions of maximum $\mathrm{SO}_{2}$ abundance (at the same location on the disk, as shown in Fig. 14) correspond to mixing ratios of $180 \mathrm{ppb}$ and $250 \mathrm{ppb}$ respectively, while the region of $\mathrm{SO}_{2}$ minimum abundance is fitted with a mixing ratio lower than $120 \mathrm{ppb}$. In the three cases, a cutoff is needed at $67 \mathrm{~km}$ to fit the data. This figure confirms that there is a significant local increase of the $\mathrm{SO}_{2}$ abundance within the cloud over a timescale of $30 \mathrm{~min}$.

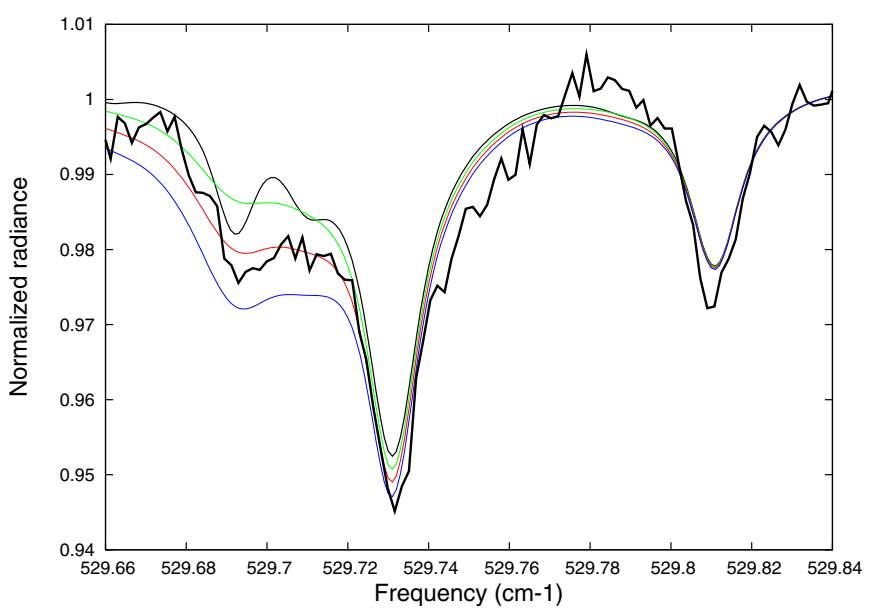

Fig. 17. Spectral fit of the $\mathrm{SO}_{2}$ doublet observed at $529.7 \mathrm{~cm}^{-1}$ on October 4, 19:40 UT (maximum $\mathrm{SO}_{2}$ area) Thick black line: TEXES data; thin black line: Models (nominal thermal profile, thin lines): $\mathrm{SO}_{2}=50 \mathrm{ppm}$, constant with height (black); $\mathrm{SO}_{2}=120 \mathrm{ppb}+$ cutoff (green); $\mathrm{SO}_{2}=180 \mathrm{ppb}+$ cutoff (red); $\mathrm{SO}_{2}=250 \mathrm{ppb}+$ cutoff (blue). The cutoff is located at $67 \mathrm{~km}(T=220 \mathrm{~K})$.

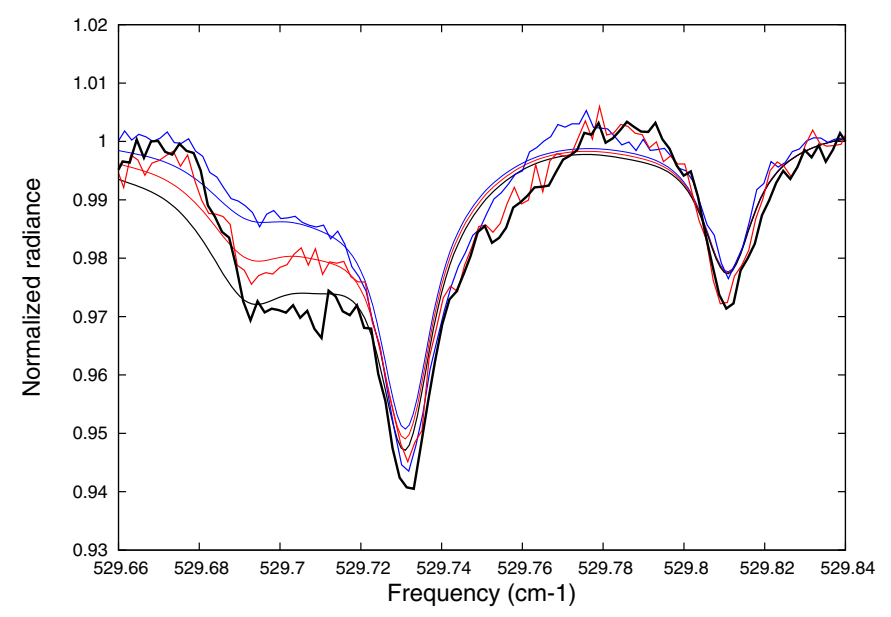

Fig. 18. Spectral fit of the $\mathrm{SO}_{2}$ doublet observed at $529.7 \mathrm{~cm}^{-1}$ on October 4. Thick black line: TEXES spectrum (maximum $\mathrm{SO}_{2}$ area), 20:10 UT. Thick red line: TEXES spectrum (maximum $\mathrm{SO}_{2}$ area), 19:40. Thick blue line: TEXES data (minimum $\mathrm{SO}_{2}$ area), 20:10). Thin lines: Models (nominal thermal profile): $\mathrm{SO}_{2}=250 \mathrm{ppb}+$ cutoff (black); $\mathrm{SO}_{2}=180 \mathrm{ppb}+$ cutoff (red); $\mathrm{SO}_{2}=120 \mathrm{ppb}+$ cutoff (blue). The cutoff is located at $67 \mathrm{~km}(T=220 \mathrm{~K})$.

\section{Discussion}

\subsection{Thermal structure}

The temperature profile retrieval of the October data implies the presence of an isothermal/inversion layer above the cloud in the $60-75 \mathrm{~km}$ region. At the cloudtop, the temperature difference between the low latitude and high latitude profile is about $10 \mathrm{~K}$ (Figs. 5 and 6). The comparison between the cloudtop temperature at high latitude $(70 \mathrm{~N}$ and $70 \mathrm{~S})$ between January and October, i.e. between evening and morning, can also be estimated from Fig. 3, using the continuum flux at these latitudes. At $7 \mu \mathrm{m}$, the fluxes are about $3 \mathrm{erg} \mathrm{s}^{-1} / \mathrm{cm}^{2} / \mathrm{sr} / \mathrm{cm}^{-1}$ on the evening side and $2 \mathrm{erg} \mathrm{s}^{-1} / \mathrm{cm}^{2} / \mathrm{sr} / \mathrm{cm}^{-1}$ on the morning side. This corresponds to a temperature difference of $10 \mathrm{~K}$ at the cloudtop, in agreement with the profiles shown in Figs. 5 and 6. This temperature difference results from the effect of the cold polar collar 
which is interpreted by Migliorini et al. (2012) and Yamamoto $\&$ Takahashi (2012) as a cold diurnal longitudinal wave. Our results can be compared with the cloudtop temperatures reported by Migliorini et al. (2012) at high latitude for dawn and dusk, using VIRTIS-H data (Fig. 3 of their paper). In spite of the partial coverage in local hours, their results show a tendency for a decrease of the cloudtop temperatures (at 100 mbar) between evening and morning from about $230 \mathrm{~K}$ to $220 \mathrm{~K}$. The same trend also appears in GCM simulations shown at a slightly higher altitude (Fig. 3 of their paper). The results shown by Migliorini et al. (2012) are thus consistent with the present analysis.

Figure 5 shows a comparison of our retrieved thermal profile at low latitude with different data sets: (1) the VIRA equatorial profile as a function of altitude (Seiff et al. 1985); (2) the equatorial profile retrieved by Irwin et al. (2008) from VIRTIS-M data in the $\mathrm{CO}(1-0)$ band; (3) the VeRa thermal profiles reported by Lee et al. (2012) and Piccialli et al. (2012). There is a noticeable difference between our profile and the VIRA and VeRA profiles, especially for temperatures higher that $215 \mathrm{~K}$. This temperature corresponds in our model to altitudes below $70 \mathrm{~km}$. Our profile, however, is in good agreement with the profile retrieved by Irwin et al. (2008) from the VIRTIS-M data. It is also very close to the one inferred by Encrenaz et al. (2011b) from the VIRTIS-H data in the same spectral range, which was used as a first guess in our January analysis (E12). Our thermal profile is constrained by two parameters: the temperature of the cloud level supposed to have an infinite opacity, which is directly inferred from our continuum temperature, and (2) several $\mathrm{CO}_{2}$ lines of different depths which, combined together, are used to retrieve both the pressure of the cloud level and the temperature gradient. We have no information about the atmosphere below the cloud level.

Figure 6 shows the same comparison as Fig. 5 for high latitudes. Our profile is, again, definitely colder than the VIRA and VeRa profiles but also, this time, colder than the VIRTIS profile (Irwin et al. 2008). Note that, at high latitudes, very different thermal profiles are reported from the VeRA database, which most likely translates to actual temporal variations.

We do not see how to reconcile our temperatures with those of the other models, as this would require a temperature increase of about $20 \mathrm{~K}$, which would imply an increase of the continuum flux by a factor 2 , well above the uncertainty associated with the absolute calibration of the instrument. We rather interpret the differences seen in Figs. 5 and 6 as the result of temporal effects. These temporal variations are certainly present at high latitude, as illustrated by the maps of the $\mathrm{CO}_{2}$ line depths taken in January and October 2012 (Fig. 4). The 7- $\mu$ m continuum maps, although probably more affected by systematic effects than the line depth ratio maps, also tend to indicate a significant change in the cloud top temperatures at high latitudes between January and October 2012 (Fig. 3).

\section{2. $H D O$}

As shown in Fig. 9, the HDO map of October 5, 2012 is remarkably homogeneous, and shows no significant difference with the two HDO maps of January 10 and 12, 2012. The mean $\mathrm{H}_{2} \mathrm{O}$ mixing ratio inferred from this map is $1.0+/-0.25 \mathrm{ppm}$ (Fig. 11) (assuming a $\mathrm{D} / \mathrm{H}$ ratio of 200 times the terrestrial value), a value also consistent (although a bit smaller) than the result of January 2012 (HDO = $1.5+/-0.75$ ppm). In E12, we pointed out that the January HDO maps, especially the one of January 12, indicated a possible limb brightening (Fig. 9). We wondered if this effect, if real, might be due to an increase of the $\mathrm{D} / \mathrm{H}$ ratio as a function of altitude above the clouds, as was reported from Venus Express SPICAV observations (Bertaux et al. 2007). It turns out that the October data show no evidence of this effect. It must be also reminded that the signal-to-noise of the $7-\mu \mathrm{m}$ October data was not as good as the January ones. Further measurements with a higher signal-to-noise ratio will be needed to investigate whether the effect is real or not, and whether it may vary with time.

As pointed out in $\mathrm{E} 12$, the mean $\mathrm{H}_{2} \mathrm{O}$ mixing ratios inferred by the TEXES data, assuming a D/H ratio of 200 times the terrestrial value, are consistent with previous measurements above the clouds from space (Fedorova et al. 2008; Cottini et al. 2012) and from the ground (Krasnopolsky 2010; Matsui et al. 2012). Our result of October 2012 confirms the lack of variability of the water content on a timescale of several months. Also, we do not confirm the latitudinal variation reported by Krasnopolsky (2010), who found a factor of 2 increase of the water content between mid and high latitudes.

\section{3. $\mathrm{SO}_{2}$}

The $\mathrm{SO}_{2}$ maps recorded at $7 \mu \mathrm{m}$ in October (Fig. 13) confirm the results of the January data (Fig. 12). Individual maps show local variations by a factor as high as 5 , and the maximum local $\mathrm{SO}_{2}$ mixing ratio is about $100 \mathrm{ppb}$ at the cloud level (Fig. 15), as inferred from the January data. The difference between the two data sets is that the October $\mathrm{SO}_{2}$ maps are more patchy, which can be explained by their shorter integration time: co-added together, the two maps of October 5 would show a map comparable with the January ones. The new results is that the $\mathrm{SO}_{2}$ spatial distribution shows significant variations over a timescale shorter than two hours. As pointed out in E12, this high variability is probably due to the very short photochemical timescale of $\mathrm{SO}_{2}$, typically in the range of hours, and possibly also to dynamical effects.

The $\mathrm{SO}_{2}$ maps recorded at $19 \mu \mathrm{m}$ (Fig. 14) provide a complementary information about the $\mathrm{SO}_{2}$ variability. The two maps of October 5 show a remarkable similarity. The spatial distribution is much less patchy than at $7 \mu \mathrm{m}$. The comparison between both data sets, at $19 \mu \mathrm{m}$ and $7 \mu \mathrm{m}$, brings information upon the transfer of $\mathrm{SO}_{2}$ from within the cloud (at about $57 \mathrm{~km}$ ) up to the cloud top, a few kilometers above. Another striking result is the difference between the two $\mathrm{SO}_{2}$ maps of October 4, taken 30 min apart. A significant increase of $\mathrm{SO}_{2}$ is visible on a large fraction of the Venus disk. As shown in Fig. 18, it implies a local increase of the $\mathrm{SO}_{2}$ mixing ratio by about 40 percent in this area. We have to note, however, that a single $\mathrm{SO}_{2}$ doublet was available in our data of October 4 , so we could not perform the comparison between two $\mathrm{SO}_{2}$ transitions as we did in the case of the 7- $\mu \mathrm{m}$ analysis (Fig. 13). Further measurements will be necessary to confirm the short-term variations of $\mathrm{SO}_{2}$ at $19 \mu \mathrm{m}$.

Another important information can be retrieved from the $\mathrm{SO}_{2}$ spectra. As shown in Figs. 16 and 17, a depletion of $\mathrm{SO}_{2}$ is required to fit the data, both at 7 and $19 \mu \mathrm{m}$. The two data sets can be fitted with a depletion of $\mathrm{SO}_{2}$ above the altitude level of $67 \mathrm{~km}(T=220 \mathrm{~K}, P=37$ mbars $)$. Calculations show that the $\mathrm{SO}_{2}$ mixing ratio above this level cannot be more than a few $\mathrm{ppb}$. We note that, as shown in E12, such a depletion was not required to fit the January data. However, different $\mathrm{SO}_{2}$ transitions were used in our previous analysis. The $1345 \mathrm{~cm}^{-1}$ region was also observed on January 12. Figure 19 shows a comparison of the spectra of January 12 and October 5, both integrated over the disk, in this spectral range. In the January 12 spectrum, in addition to the $\mathrm{SO}_{2}$ doublet at $1345.12 \mathrm{~cm}^{-1}$, another doublet is detected at $1345.02 \mathrm{~cm}^{-1}$. This feature is hidden in the October data because 


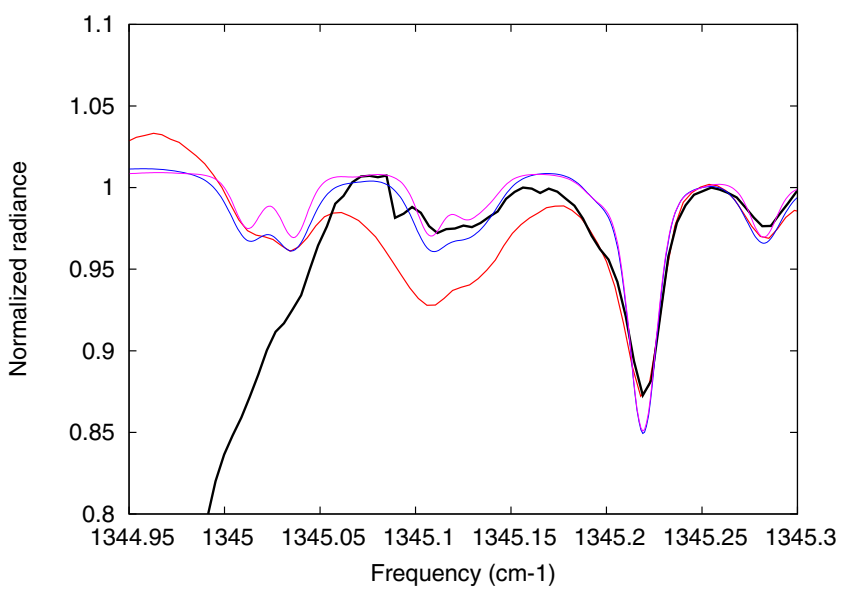

Fig. 19. TEXES spectra, integrated over the disk, recorded in the 1344.95-1345.30 $\mathrm{cm}^{-1}$ on Juanuary 12 (thick red line) and October 5 (thick black line). Data are compared with different models (thin lines): blue: $\mathrm{SO}_{2}=150 \mathrm{ppb}+$ cutoff (same model as in Figs. 14 and 15); Magenta: constant $\mathrm{SO}_{2}$ mixing ratio, $\mathrm{SO}_{2}=35 \mathrm{ppb}$ (same as in Fig. 15, thin black line). It can be seen that, for both observed spectra, a better fit is obtained when a cutoff is applied at $67 \mathrm{~km}$. The drop of the signal on the October 5 TEXES spectrum is due to a strong telluric band. We note that the signal-to-noise of the October spectrum is not as good as in the January spectrum, due to poor atmospheric conditions. The discrepancy observed around $1345.1 \mathrm{~cm}^{-1}$ between the January data and the models is puzzling, and seems to be due to a continuum fluctuation.

of the shift of the telluric absorption band (also much stronger in October than in January) due to the different Doppler velocities. It can be seen that there is no significant difference in the shapes of the doublets between January and October 2012; the TEXES data at $1345.05 \mathrm{~cm}^{-1}$ are better fitted with a $\mathrm{SO}_{2}$ distribution including a cutoff above the cloud than with a constant $\mathrm{SO}_{2}$ mixing ratio. In the case of $\mathrm{SO}_{2}$ singlets, as shown at $1345.28 \mathrm{~cm}^{-1}$, both $\mathrm{SO}_{2}$ distributions fit the data. As single $\mathrm{SO}_{2}$ lines were used in our analysis of the January data, we were not able to identify the cutoff, but the analysis of the $1345.02 \mathrm{~cm}^{-1}$ doublet shows that it was indeed also present in January. Figure 19 also indicates comparable global $\mathrm{SO}_{2}$ abundances in January 12 and October 5. The depression observed at $1345.12 \mathrm{~cm}^{-1}$ in the January spectrum is not believed to be due to an excess of $\mathrm{SO}_{2}$, as the $\mathrm{SO}_{2}$ features at 1345.02 and $1345.28 \mathrm{~cm}^{-1}$ lead to comparable abundances of $\mathrm{SO}_{2}$. It is more likely due to a fluctuation of the continuum. We note than the depletion of $\mathrm{SO}_{2}$ above the clouds was already observed by other authors (Belyaev et al. 2012) and predicted by photochemical models (Zhang et al. 2012). The altitude of the cutoff inferred from the present study, however, tends to be lower than previously derived. This difference will require further investigation and complementary measurements.

Finally, the $\mathrm{SO}_{2}$ mixing ratios inferred at 19 and $7 \mu \mathrm{m}$, both for the integrated disks (Fig. 16) and for localized areas (Fig. 18) are in global agreement. As mentioned in our previous study (E12), they are also in overall agreement with other past and recent measurements in the same altitude range, from the Venera 15 measurements (Zasova et al. 1993) to the more recent SPICAV data aboard Venus Express, in the UV (Marcq et al. 2011) and in the infrared (Belyaev et al. 2012), as well as the ground-based measurements (Krasnopolsky 2010). All studies illustrate the high variability of $\mathrm{SO}_{2}$ on both short and long time scales; our results show that very short timescales are involved in the behavior of $\mathrm{SO}_{2}$ on Venus.

The present analysis leads to three conclusions: (1) The thermal profile at high latitude shows significant differences between
January and October 2012, probably associated with the local hour of the observations: the cold diurnal longitudinal wave, associated with the polar collar is expected to be enhanced in morning observations, as compared with the evening data; (2) A cutoff in the $\mathrm{SO}_{2}$ vertical distribution, a few kilometers above the cloud top, is needed to fit both the $7-\mu \mathrm{m}$ and $19-\mu \mathrm{m}$ data of October 2012, and also fits the January 2012 data; (3) local variations of the $\mathrm{SO}_{2}$ mixing ratio are detectable on timescales shorter than a couple of hours. In the future, we plan to repeat these observations in order to confirm these three effects. In a next step, we plan to use the EXES instrument aboard the stratospheric airborne observatory SOFIA in order to observe simultaneously $\mathrm{HDO}$ and $\mathrm{H}_{2} \mathrm{O}$ transitions and determine independently the water mixing ratio and the $\mathrm{D} / \mathrm{H}$ ratio above the clouds.

Acknowledgements. T.E., M.J.R. and C.d.W. were visiting astronomers at the InfraRed Telescope Facility, which is operated by the University of Hawaii under Cooperative Agreement no. NNX-08AE38A with the National Aeronautics and Space Administration, Science Mission Doctorate, Planetary Astronomy Program. We thank the IRTF staff for the support of TEXES observations. Observations with TEXES were supported by NSF Grants AST-0607312 for JHL and AST-0708074 for M.J.R. T.E. and B.B. acknowledge support from CNRS, and T.F. aknowledges support from UPMC and IUF. T.W. acknowledges support from the University Versailles-Saint-Quentin. T.E. and T.W. acknowledge support from the Programme National de Planétologie of INSU/CNRS.

\section{References}

Belyaev, D. A., Korablev, O., Fedorova, A., et al. 2008, J. Geophys. Res., 113, E00B25

Belyaev, D. A., Montmessin, F., Bertaux, J.-L., et al. 2012, Icarus, 217, 740

Bertaux, J.-L., Vandaele, A.-C., Korablev, O., et al. 2007, Nature, 450, 646 Bézard, B., \& de Bergh, C. 2007, J. Geophys. Res., 112, E04S07

Bézard, B., de Bergh, C., Crisp, D., \& Maillard, J.-P. 1990, Nature, 345, 508

Cottini, V. Igniatiev, N., Piccioni, G., et al., 2012, Icarus, 217, 561

Crisp, D. 1986, Icarus, 67, 484

Encrenaz, T., Bézard, B., Greathouse, T. K., et al. 2004, Icarus, 170, 424

Encrenaz, T., Greathouse, T. K., Richter, M. J., et al. 2008, Icarus, 195, 547

Encrenaz, T., Greathouse, T. K., Richter, M. J., et al. 2011a, A\&A, 530, A37

Encrenaz, T., Drossart, P., Erard, S., et al. 2011 b, Communication presented at the EPSC-DPS Conference, Nantes, October 3-7, 2011

Encrenaz, T., Greathouse, T. K., Roe, H., et al. 2012a, A\&A, 543, A153

Encrenaz, T., Greathouse, T. K., Lefevre, F., \& Atreya, S. K. 2012b, Planet. Space Sci., 68, 3

Esposito, L. W. 1984, Science, 223, 1072

Fedorova, A., Korablev, O., Vandaele, A.-C., et al. 2008, J. Geophys. Res., 113, E00B25

Irwin, P. J., de Kok, R., Negrao, A., et al. 2008, J. Geophys. Res. 113, E00B01

Jacquinet-Husson, N., Scott, N., Chedin, A., et al. 2008, J. Quant. Spectr. Radiat. Transf., 109, 1043

Krasnopolsky, V. A. 2007, Icarus, 191, 25

Krasnopolsky, V. 1. 2010, Icarus, 209, 314

Lacy, J. H., Richter, M. J., Greathouse, T. K., et al. 2002, PASP, 114, 153

Lee, Y. J., Titov, D. V., Tellmann, S., et al. 2012, Icarus, 217, 599

Liang, M. C., \& Yung, Y. L. 2009, J. geophys. Res., 114, E00B28

Marcq, E., Belyaev, D. A., Montmessin, F., et al. 2011, Icarus, 211, 58

Matsui, H., Iwagami, N., Hosouchi, M., et al. 2012, Icarus, 217, 610

Migliorini, A., Grassi, D., Montabone, L., et al. 2012, Icarus, 217,640

Mills, F. P., Esposito, L. W., \& Yung, Y. K. 2007, in Exploring Venus as a Terrestrial Planet, Geophysical Monograph Series, 176, 73

Nakazawa, T., \& Tanaka, M. 1982, J. Quant. Spectr. Radiat. Transf., 28, 409

Piccialli, A., Tellmann, S., Titov, D. V., et al. 2012, Icarus, 217, 669

Rothman, L. S., Rinsland, C. P., Goldman, A., et al. 2005, J. Quant. Spectr. Radiat. Transf., 60, 665

Seiff, A., Schofield, J. T., Kliore, A. J., Kliore, et al. 1985, Adv. Space Res., 5, 3

Varanasi, P. 1971, J. Quant. Spectr. Radiat. Transf., 11, 223

Yamamoto, M., \& Takahashi, M. 2012, Icarus, 217, 702

Zhang, X., Liang, M.-C., Montmessin, F., et al. 2010, Nature Geosci. Lett., 3, 834

Zhang, X., Liang, M. C., Mills, F. P., et al. 2012, Icarus, 217, 714

Zasova, L. V., Moroz, V. I., Esposito, L. W., \& Na, C. Y. 1993, Icarus, 105, 92 